\title{
Adipose-derived Stromal Vascular Fraction Cells
}

National Cancer Institute

\section{Source}

National Cancer Institute. Adipose-derived Stromal Vascular Fraction Cells. NCI

Thesaurus. Code C124992.

A population of stromal vascular fraction (SVF) cells derived from autologous adipose tissue, with potential tissue regenerative activity. SVF cells are obtained through liposuction and contain multiple cell types, including adipose-derived stem cells (ADSCs), mesenchymal and endothelial progenitor cells, leukocyte subtypes, lymphatic cells, pericytes, and vascular smooth muscle cells. The SVF cells are processed in such a way as to contain a reproducible and consistent composition of heterogeneous cells. Upon processing and administration, the adipose-derived SVF cells can differentiate into different tissue types, support neovascularization, replace cells and repair injured issue. 